\title{
As similaridades estruturais decorrentes dos efeitos do isomorfismo mimético nos programas de Pós-Graduação em Administração
}

\section{The structural similarities arising out of the effects of mimetic isomorphism on postgraduate programs in Administration}

\section{Danieli Artuzi Pes Backes}

Universidade Federal de Mato Grosso (UFMT)

email:backes.dani@gmail.com

\section{Fernando Antonio Ribeiro Serra}

Universidade Nove de Julho (UNINOVE)

email:fernandoserra@gmail.com

\author{
Isabel Cristina Scafuto \\ Universidade Nove de Julho (UNINOVE) \\ email: isabelscafuto@gmail.com
}

\section{Mauricio Andrade de Lima}

Universidade Alto Vale do Rio do Peixe (UNIARP)

email:mauricio.andrade@uniarp.edu.br

\section{RESUMO}

Este estudo teve como objetivo identificar a presença de isomorfismo mimético a partir das semelhanças estruturais dos currículos dos Programas de Pós-Graduação em Administração-PPGA, e verificar se o mimetismo contribui para um desempenho semelhante no ranking da CAPES. Metodologicamente, utilizou-se estatística descritiva e análise de agrupamento com a técnica de Co-plot como procedimento de apresentação e análise de dados. Como resultado, identificamos quatro grupos de PPGAs e a similaridade estrutural intragrupo. Percebeu-se na formação de clusters, a identificação de um alto nível de similaridade entre os programas e a aceitação parcial de que pertencer a um determinado grupo pode se refletir no desempenho do PPG. Conclui-se que a postura diferenciada de cada grupo isomórfico observado não implica desempenho semelhante a todos os componentes. Portanto, a proposição principal do estudo reside na constatação de que a presença de isomorfismo estrutural não tem correlação com o desempenho e que não é evidente obter os mesmos resultados a partir do espelhamento de estruturas e procedimentos das organizações mais legitimadas.

Palavras-Chave: Isomorfismo, Teoria Institucional, Isomorfismo Mimético, Pós-Graduação em Administração, Similaridades Estruturais

\section{ABSTRACT}

This study aimed to identify the presence of mimetic isomorphism from the structural similarities of the curricula of the Postgraduate Programs in Administration-PPGA, and if the mimicry contributes to a similar performance in the CAPES ranking. Methodologically, we used descriptive statistics and cluster analysis with the Co-plot technique as a data presentation and analysis procedure. As a result, we identified four groups of PPGAs and the structural similarity between them. We also noticed that the formation of clusters, the identification of a high level of similarity among the programs, and the partial acceptance that belonging to a given group can be reflected in the performance of PPGP. We conclude that the differentiated posture of each observed group of each isomorphic group does not mean performance similar to all the components. Therefore, we argue that it is not evident to obtain the same results from the mirroring of structures and procedures of the reference organizations.

Key-words: Isomorphism, Institutional Theory, Mimetic Isomorphism, Post-Graduation in Administration, Structural Similarities 


\section{INTRODUÇÃO}

$\mathrm{O}$ isomorfismo mimético surge em ambientes regulamentados e com alto grau de incerteza e diz respeito à realização da conformidade através da imitação (HAVEMAN, 1993). Em outras palavras, o isomorfismo mimético, se estabelece com maior frequência em um campo com elevada ambiguidade e pode estar associado ao desejo de se assemelhar às instituições mais bem-sucedidas com a intenção de aumentar as chances de sucesso (DIMAGGIO; POWELL, 1983; ALMEIDA; CALLADO, 2017). Essa prática existe quase que naturalmente entre as organizações e tanto maior tende a ser quanto mais regulamentado o campo organizacional (PECI, 2006). O ensino superior é um desses campos onde as pressões institucionais moldam o comportamento das organizações (ANAFINOVA, 2020; GEORGE, CASTRO, RINCON, 2019; LARRÁN, HERRERA, ANDRADES, 2015).

No Brasil, os cursos programas de pós-graduação stricto sensu são avaliados pela Coordenação de Aperfeiçoamento de Pessoal de Nível Superior - CAPES. Embora o sistema seja considerado exitoso e relevante para a produção do conhecimento científico, onde seus mecanismos têm provocado efeitos significativos na organização dos programas; nas atividades de ensino, pesquisa e orientação, bem como nas relações estabelecidas entre os indivíduos e entre as instituições (MACCARI, ET AL., 2009; NASCIMENTO, 2010), existem críticas, como a de que o sistema é padronizado para todas as áreas do conhecimento.

Esses estudos corroboraram com o de Spagnolo e Calhau (2002), que ressaltam a heterogeneidade entre as diferentes áreas do conhecimento e a diversidade quanto as questões econômicas e de acesso aos recursos. "Se a moldura é única, cedo ou tarde haverá um único modelo ou formato de programa. E isto parece estar na contramão da diversidade e da própria concepção de universidade, que deriva de universal e não de único" (SGUISSARDI, 2006, p. 68). O sistema avaliativo pode gerar pressões e incertezas para os programas porque compara os desempenhos por meio de um ranking (MACCARI, ET AL., 2009; SAUDER, ESPELAND, 2009), cujo conceito obtido se reflete na capacidade de captação de recursos (DIAS SOBRINHO, 2003; LARRÁN, HERRERA, ANDRADES, 2015).

Estudos como os de Acer e Güçlü (2017), Anafinova (2020), Atkinson (2008), Ganga, Pedraja-Rejas, Quiroz e Rodríguez- Ponce (2017), George; Castro e Rincon (2019), Larrán, Herrera, Andrades (2015), Papadimitriou e Westerheijden (2010) buscaram identificar a presença do isomorfismo mimético e seus efeitos sobre as instituições de ensino superior (IES). Todos esses estudos usaram uma gama de variáveis para testar a existência do isomorfismo mimético ou a influência dos mecanismos isomórficos sobre as instituições educacionais, mas não verificaram o desempenho das IES em rankings de avaliação, a fim de investigar se a adoção de modelos, estruturas e práticas espelhadas em instituições legitimadas asseguram desempenho superior, como proxy do conceito de legitimidade, isto é, a aceitação de uma organização pelo seu ambiente externo (DIMAGGIO, POWELL, 1983; MEYER, ROWAN, 1977).

Esse, portanto, é o objetivo deste estudo, que pretende suprir essa lacuna empírica e colaborar com a discussão sobre as práticas voluntárias de assemelhamento de estruturas decorrentes das incertezas presentes em ambientes regulamentados, com vistas a verificar a relação entre as estruturas isomórficas e o desempenho superior. Desse modo, se pretende contribuir conceitualmente com o estabelecimento da relação entre comportamentos isomórficos e desempenho. Para tanto, o estudo foi organizado da seguinte forma: além dessa introdução, apresentamos o referencial teórico, que sustenta o arcabouço teórico do estudo. Em seguida expomos os métodos utilizados para a coleta e tratamento dos dados, seguidos da apresentação e discussão dos resultados e por fim, as considerações finais do estudo.

\section{ISOMORFISMO MIMÉTICO}

Da visão neo-institucionalista, nascente das publicações de Meyer e Rowan (1977) e de DiMaggio e Powell (1983), emergiu a abordagem isomórfica. O isomorfismo se trata de pressões que conduzem uma organização a se tornar semelhante à outra em razão das condições ambientais que incidem sobre 
seu espaço de atuação (DIMAGGIO; POWELL, 1983; MARTÍNEZ-FERRERO, GARCÍA-SÁNCHEZ). Dimaggio e Powell (1983) dividem as mudanças organizacionais isomórficas de três formas: 1. Isomorfismo coercitivo, que surge a partir de influências políticas e necessidade de legitimação; 2. Isomorfismo normativo, que está associado à profissionalização $\mathrm{e}$ disseminação de ideias e práticas; e 3. Isomorfismo mimético, que diz respeito às ações padronizadas em resposta às incertezas.

Segundo Meyer e Rowan (1977, p. 340) “muitas estruturas organizacionais formais surgem como reflexos de regras institucionais racionalizadas" e essas regras, ao serem assimiladas pelas organizações, as tornam legitimadas, e as estabilizam, de modo a ampliar suas perspectivas de sobrevivência e acesso a recursos. Contudo, a absorção das regras institucionais pode tornar as organizações isomórficas. Apesar de existir três classificações para o isomorfismo institucional, sendo coercitivo, normativo e mimético, nesse estudo vamos nos concentrar no isomorfismo mimético, que é compreendido como a imitação ou implantação do modelo de outras organizações e ocorre diante de incertezas, objetivos ambíguos e tecnologias mal compreendidas (DIMAGGIO; POWELL, 1983).

Dentre os três tipos de isomorfismos, o mimético é o único voluntário, e ocorre porque as organizações decidem se espelhar nas práticas e estruturas das organizações mais legitimadas. No cenário onde não há clareza na relação entre meios e fins ou quando os objetivos organizacionais não estão bem definidos, as organizações costumam observar as práticas das outras e julgar se as ações das organizações estruturalmente equivalentes são adequadas (HAN, 1994), e dessa forma, podem economizar com custos de pesquisa, ao substituir as regras institucionais pelas regras técnicas (HAVEMAN, 1993).

Quando as organizações se encontram em um campo bem estruturado onde existem pressões externas que variam desde avaliação, exames ou até outras formas de acreditação, tendem a agir defensivamente e atuar de maneira similar às outras organizações que conseguem obter sucesso, e optam por deixar o planejamento estratégico em segundo plano para atender às leis e normas de regulamentação (LARRÁN, HERRERA, ANDRADES, 2015; MACCARI ET AL.,
2014). Conforme as pressões regulatórias aumentam, as organizações elevam o grau de formalização de normas e procedimentos (FRUMKIN; GALASKIEWICZ, 2004) e incorrem em mudanças cada vez mais isomórficas. Esse é o caso do campo organizacional do ensino superior, onde agências, principalmente ligadas ao governo ou de acreditações internacionais, agem de forma a direcionar as instituições, inclusive incentivam a imitação de grandes universidades de status superior por universidades de menor status (ANAFINOVA, 2020).

\subsection{Isomorfismo Mimético nas Instituições de Ensino Superior e as classificações}

Estudos para identificação das forças isomórficas em instituições de ensino superior tem sido feito por muitos autores em vários países do mundo. As constatações, em geral, são sempre positivas para a presença de isomorfismo institucional nessas instituições, em especial isomorfismo coercitivo e mimético. No quadro a seguir (Figura 1) são elencados os principais e mais recentes estudos da área, que permitem a compreensão sobre a evolução dos estudos nesse campo organizacional.

As pressões externas que criaram as condições para um ambiente de incertezas e ambiguidades no ensino superior se iniciaram nas últimas três décadas com a adoção dos princípios de certificações de qualidade (JARVIS, 2014) inspirados nas ferramentas de gestão e controle das empresas japonesas (LARRÁN, HERRERA, ANDRADES, 2015). A busca pela qualidade como um instrumento separado da gestão universitária, inserido na política governamental, começou na década de 1970 nos Estados Unidos (ISHIKAWA, 2009), em 1980 na Europa (LARRÁN, HERRERA, ANDRADES, 2015) e na Austrália (CROUCHER; WOELERT, 2016) e a partir de 1990 nos países africanos (MIGUEL, TAMBE, DA COSTA, 2021).

No Brasil, o controle mais incisivo teve início a partir de 1990, principalmente nos níveis educacionais responsáveis pela produção de pesquisas científicas (MACCARI ET AL., 2014; SPAGNOLO; CALHAU, 2002; SGUISSARDI, 2006; MOROSINI, 2001). A reestruturação e mudança de gestão do principal órgão normativo do campo organizacional 


\begin{tabular}{|c|c|}
\hline Autor - obra & Principais resultados \\
\hline $\begin{array}{l}\text { Miguel, Tambe, da } \\
\text { Costa, } 2021\end{array}$ & $\begin{array}{l}\text { A partir de dados históricos fornecidos pelo Ministério da Ciência e Tecnologia, Educação Superior e Profissional } \\
\text { e Técnica de Moçambique de } 2008 \text { a } 2015 \text {, os autores avaliaram a expansão e as tendências do Ensino Superior } \\
\text { enraizado em práticas de isomorfismo refletidas na diversificação e fragmentação do sistema. As análises identifi- } \\
\text { caram práticas coercitivas e miméticas, revelados pela expansão drástica de } 2 \text { para } 49 \text { instituições, que desde } 1995 \\
\text { foram fragmentadas e reestruturadas em resposta ao mercado de trabalho, forças políticas, forças econômicas e do } \\
\text { mercado educacional. }\end{array}$ \\
\hline Anafinova, 2020 & $\begin{array}{l}\text { Após análise das missões universitárias e estratégias de desenvolvimento a fim de identificar o papel do governo e } \\
\text { das agências de acreditação no desenvolvimento do isomorfismo nas instituições de ensino superior do Cazaquis- } \\
\text { tão, concluiu que as universidades nacionais são empurradas para um modelo anglo-americano de universidade de } \\
\text { pesquisa, o que conduz o campo organizacional para o isomorfismo. }\end{array}$ \\
\hline Marini, 2020 & $\begin{array}{l}\text { O autor examinou as consequências das grandes reformas do ensino superior na França e na Espanha, a partir do } \\
\text { sistema de avaliação da carreira acadêmica e constatou que as implicações para a formulação de políticas são rele- } \\
\text { vantes quando esses dois países são comparados, sugerindo que abordagens políticas mais radicais (isomorfismo } \\
\text { coercitivo, o caso francês) não resultam em mais mudanças nas práticas de avaliação acadêmica do que as miméti- } \\
\text { cas (o caso espanhol), além de que o isomorfismo coercitivo encontrou mais atritos em sua implementação. }\end{array}$ \\
\hline $\begin{array}{l}\text { George; Castro, Rincon, } \\
2019\end{array}$ & $\begin{array}{l}\text { Com base em entrevistas com administradores que representam } 40 \text { programas de intervenção do programa de } \\
\text { Ciência, Tecnologia, Engenharia e Matemática (STEM) em } 10 \text { universidades nos Estados Unidos, o estudo examinou } \\
\text { as origens do programa através da lente do isomorfismo. As análises forneceram evidências de isomorfismo miméti- } \\
\text { co e coercitivo e pouca evidência de alocação de recursos e tomada de decisão estratégica. }\end{array}$ \\
\hline $\begin{array}{l}\text { Da Silva, Mussi, Casa- } \\
\text { grande, de Lima (2019) }\end{array}$ & $\begin{array}{l}\text { A partir de análise estatística descritiva dos dados de relatórios institucionais de uma IES pública brasileira, os autores } \\
\text { verificaram que o processo de autoavaliação institucional tem indícios de mecanismos isomórficos coercitivos e } \\
\text { miméticos. Em razão do percentual de não apropriação funcional dos servidores, acima dos } 40 \% \text { durante o período } \\
\text { de estudo, concluíram que esses mecanismos isomórficos têm influenciado as etapas de realização e divulgação dos } \\
\text { resultados do processo autoavaliativo institucional. }\end{array}$ \\
\hline Acer; Güçlü, 2017 & $\begin{array}{l}\text { Usando dados longitudinais da classificação das universidades da Turquia por estatísticas de desempenho acadê- } \\
\text { mico, os autores analisaram instituições estabelecidas antes de } 1983 \text { e depois de 2006, períodos normativos de } \\
\text { diferentes intensidades. A análise mostrou que o aumento da quantidade não foi acompanhado pela qualidade, e se } \\
\text { verificou um modelo de universidade altamente burocrático, o que torna o sistema de ensino superior isomórfico. }\end{array}$ \\
\hline $\begin{array}{l}\text { Ganga, Pedraja-Rejas, } \\
\text { Quiroz, Rodríguez- } \\
\text { Ponce, } 2017\end{array}$ & $\begin{array}{l}\text { Os autores examinaram os comentários feitos por avaliadores no processo de Acreditação Institucional de sete uni- } \\
\text { versidades chilenas. Os resultados mais relevantes sugerem que há evidências claras para a presença de mecanismos } \\
\text { isomórficos nas universidades. }\end{array}$ \\
\hline $\begin{array}{l}\text { Scafuto, Backes e } \\
\text { Maccari, } 2017\end{array}$ & $\begin{array}{l}\text { Os autores avaliaram a existência de grupos isomórficos nas IES participantes do ranking da América Economia, a } \\
\text { partir das semelhanças do conteúdo programático de seus MBAs e constataram a formação de três grupos isomórfi- } \\
\text { cos, além de comportamentos complementares idiossincráticos de algumas instituições. }\end{array}$ \\
\hline $\begin{array}{l}\text { Croucher, Woelert, } \\
2016\end{array}$ & $\begin{array}{l}\text { Com base em uma série de dados universitários e governamentais, o artigo analisou as mudanças nas estruturas } \\
\text { organizacionais acadêmicas das universidades australianas públicas. Os resultados apontaram que havia uma con- } \\
\text { vergência clara quanto às similaridades nas estruturas organizacionais formais na maioria dos campos acadêmicos } \\
\text { das universidades públicas da Austrália. }\end{array}$ \\
\hline $\begin{array}{l}\text { Larrán, Herrera, Andra- } \\
\text { des, } 2015\end{array}$ & $\begin{array}{l}\text { Os autores analisam os planos estratégicos desenvolvidos pelas universidades espanholas na última década a fim de } \\
\text { examinar até que ponto as universidades espanholas incorporaram estratégias de sustentabilidade, e se a presença } \\
\text { dessas estratégias pode estar associada às pressões institucionais. Verificou-se que a adoção das estratégias sustentá- } \\
\text { veis nas universidades espanholas pode estar ligada a pressões coercitivas e miméticas provenientes do sistema de } \\
\text { financiamento de desempenho do Estado para as universidades. }\end{array}$ \\
\hline $\begin{array}{l}\text { Papadimitriou, Wes- } \\
\text { terheijden, } 2010\end{array}$ & $\begin{array}{l}\text { Os autores empregaram uma abordagem de métodos mistos para avaliar se o uso dos padrões ISO nas universida- } \\
\text { des gregas até } 2006 \text { e a adoção de ferramentas de gestão de qualidade é consistente com as noções de isomorfis- } \\
\text { mo. Verificaram que o sistema de gestão da qualidade orientado para ISO foi adotado com sucesso nas unidades, } \\
\text { apenas se todos os três tipos de pressões neo-institucionais (coercitiva, normativa e mimética) estavam presentes. }\end{array}$ \\
\hline Atkinson, 2008 & $\begin{array}{l}\text { Fazendo uso de análise de discurso e semiótica para avaliar a cultura do ensino superior nos Estados Unidos me- } \\
\text { diante as declarações de missão e informações correspondentes nos sites das universidades, verificou a presença } \\
\text { de mecanismos isomórficos de modo que as organizações demonstraram compartilhar estruturas, componentes, } \\
\text { imagens e linguagem semelhantes. }\end{array}$ \\
\hline
\end{tabular}

Fonte: Organização dos autores com base na bibliografia (2021).

Figura 1 Estudos recentes e relevantes sobre o isomorfismo na Educação Superior 
pode ter levado a influenciar diferentes comportamentos das instituições (DACIN, 1997), tais como, aumento da competitividade na educação superior (HAMMARFELT; FREDRIK, 2015), e direcionamento das pesquisas para padrões do modelo anglo-americano de pesquisa (ISHIKAWA, 2009), o que pode gerar prejuízo ao desenvolvimento científico nacional (VOLPATO; FREITAS, 2003).

Em diferentes regiões continentais e em períodos diversos os autores elencados na Figura 1 identificaram a presença e os efeitos do isomorfismo institucional sobre a gestão de instituições de ensino superior, com especial destaque para os isomorfismos coercitivo e mimético. Todavia, os autores não mediram o impacto da adoção de práticas isomórficas sobre os resultados alcançados pelas organizações educacionais e consequente desempenho nas avaliações institucionais dos órgãos responsáveis. Pretendendo suprir essa lacuna empírica, esse estudo teve por objetivo avaliar as similaridades estruturais e compará-las ao conceito obtido no ranking de avaliação periódico da Capes. Desse modo, se pretende contribuir conceitualmente com o estabelecimento da relação entre comportamentos isomórficos e desempenho.

\subsection{Hipóteses do estudo}

No campo das pós-graduações stricto sensu, que pertence a um dos campos organizacionais mais estruturados, a CAPES é o órgão regulador e normatizador (MACCARI ET AL., 2014, MARTINS ET AL., 2014, SGUISSARDI, 2006). Assim, diante das pressões exercidas pela CAPES que vão desde a normatização para criação de novos cursos até a avaliação periódica (CAPES, 2017), supõem-se constatar a existência de isomorfismo mimético entre os programas de pós-graduação em Administração. Portanto, a primeira hipótese é a de que:

H1: Existe isomorfismo mimético entre os programas de pós-graduação stricto sensu em Administração no Brasil.

As ações de muitas organizações, onde se incluem as educacionais, têm como base o quadro social do grupo ao qual pertencem (HAN, 1994), por isso algumas estratégias são tão populares em alguns campos organizacionais (PEDERSEN; NEERGAARD; PEDERSEN; GWOZDZ, 2013). Esse é o cenário que supomos encontrar no campo educacional dos PPGAs, pois os cursos de pós-graduação brasileiros, especialmente da área da Administração, seguiam modelos similares, devido à forte influência americana adotada desde o início da fundação dos programas (DOS SANTOS; AZEVEDO, 2009), por volta de 1970. Esse fato pode ter gerado isomorfismo mimético, que se trata da intenção de assemelhar a própria estrutura à estrutura de outras organizações ou ainda seria um processo de mudanças baseadas em tendências compartilhadas entre organizações (TOLBERT; ZUCKER, 1983; BURNS; WHOLEY, 1993).

Todavia, os programas se encontram em um ambiente altamente regulamentado por órgãos governamentais, como a CAPES, que podem impedir a completa semelhança entre as estruturas e práticas. Nos últimos anos, por meio dos documentos de área, a CAPES instituiu um conjunto de orientações para aprovação de novos cursos que incluem os critérios de inovação e relevância local, regional ou nacional (CAPES, 2016). Isso impede que todos os programas mantenham estruturas semelhantes. Assim, mesmo que pertença a um campo organizacional comum, espera-se encontrar similaridades e dissimilaridades entre os PPGAs, que podem vir a se aglomerar por semelhanças estruturais estratificadas e formar diferentes agrupamentos. Portanto, na segunda hipótese sustenta-se que:

H2: Há similaridade entre as estruturas curriculares dos PPGAs que poderão formar grupos específicos com características intraorganizacionais similares e características interorganizacionais dissimilares.

No estudo realizado por Segev, Raveh e Farjoun (1999), que encontraram resultados como a formação de seis grupos distintos, compostos pelas similaridades entre os 25 principais Master of Business Administration (MBAs) americanos, como resposta ao ambiente competitivo e, no Brasil, Langrafe, Boaventura, da Silva e da Silva (2009) encontraram situação parecida entre os cursos de graduação em Administração das faculdades de São Paulo, ao identificar 
três tipos de agrupamentos, que concluíram serem formados a partir da adaptação às forças regulatórias.

Tanto as forças regulatórias quanto os aspectos competitivos, que também podem ser decorrentes da regulamentação, pelo fato de existir um ranking de diferenciação, conduzem as instituições a adotar estratégias semelhantes na busca pela legitimação. $\mathrm{O}$ reconhecimento e a legitimação podem vir a partir do bom desempenho na avaliação do órgão regulador e o fato de receber uma avaliação positiva significa maiores chances na captação de recursos (DIAS SOBRINHO, 2003; LARRÁN, ET AL., 2015), além de reconhecimento pelo processo de internalização das classificações como um processo padrão (SAUDER; ESPELAND, 2009). Assim, os gestores tenderão a mover esforços para obter um bom posicionamento no ranking da CAPES e uma das alternativas para reduzir as incertezas e aumentar as chances de sucesso, pode ser se espelhar em outra organização que presumidamente obteve êxito (PEDERSEN ET AL., 2013). Portanto, a terceira hipótese é:

H3: O pertencimento a um determinado grupo, formado a partir do isomorfismo estrutural, pode se refletir no desempenho do PPGA na avaliação da CAPES.

A seguir são explanados os procedimentos metodológicos que nortearam o estudo.

\section{PROCEDIMENTOS METODOLÓGICOS}

O presente estudo é exploratório, de natureza aplicada, quantitativa e se utiliza de estatística descritiva e análise de agrupamentos como método para coleta, apresentação e análise de dados. A estatística é uma coleção de instrumentos necessários para recolher, organizar, apresentar, explorar, descrever e interpretar um conjunto de dados (PESTANA; GAGEIRO, 2003; MURTEIRA, 1993). Quanto aos agrupamentos, por meio da classificação e categorização das matrizes curriculares dos PPGAs, ao fazer uso do método Co-plot, foram formados grupos de PPGAs aglomerados pelas similaridades curriculares, que supostamente, refletem a similaridade estrutural entre os programas.

Obs.: As disciplinas também poderão ser denominadas componentes curriculares ao longo do texto.

\subsection{Coleta de dados}

Para atender aos objetivos do estudo, os seguintes critérios foram adotados para a coleta de dados: a) As informações para mapeamento dos programas - as disciplinas cadastradas pelos PPGAs - foram coletadas na Plataforma Sucupira da CAPES, no link referente à "Coleta CAPES" - Disciplinas (CAPES, 2017a); b) Os programas selecionados para o estudo foram todos aqueles que possuíam notas que variavam de 4 a 7 na Avaliação Quadrienal de 2016 da CAPES, no total de 37 PPGAs, dentro de um universo de 65 PPGAs acadêmicos classificados como da área de Administração, Administração de Empresas, Administração e Negócios. As notas selecionadas para a pesquisa certificam que a qualidade dos programas varia de boa (conceito 4) à excelência nacional (conceito 5) e excelência internacional (conceito $6 \mathrm{e}$ 7) (CAPES, 2015).

Os dados foram coletados e tratados entre o segundo semestre de 2016 e primeiro semestre de 2017. Devido à variedade de programas que compõem a amostra, tanto em relação à idade, tamanho do corpo docente, natureza jurídica, localização geográfica, tradição, acesso a recursos, inserção regional e/ou internacional, foi necessário adotar uma série de critérios de forma a se obter um conjunto de dados confiável. Uma das maiores dificuldades foi equalizar a disparidade entre o tamanho das matrizes cadastradas pelos programas, de modo que alguns possuíam quantidade vasta, acima de 100 disciplinas, ao passo que outros apresentavam reduzidas, abaixo de 30 disciplinas. Para tanto, alguns critérios foram estabelecidos, tais como:

1. Todos os programas passaram pela primeira triagem ainda na Plataforma Sucupira onde foram observadas a data de cadastramento e encerramento das disciplinas, sendo que as que registraram duração inferior a 1 ano foram descartadas do estudo. Todas as demais datas foram incluídas, com exceção das cadastradas no ano de 2017; 2. Na planilha eletrônica os componentes curriculares foram ordenados 
em ordem alfabética para observação de disciplinas repetidas; 3. Foram eliminadas disciplinas com denominação idêntica, independente da carga horária; 4. Componentes curriculares cadastrados com a indicação de pertencerem a Minter ou Dinter e de curta duração de tempo foram desconsiderados da amostra. Houve algumas exceções no caso de PPGAs com número reduzido de disciplinas cadastradas, como por exemplo abaixo de 30; 5 . Não foram incluídas disciplinas cadastradas pelos programas em 2017, entretanto, algumas exceções ocorreram no caso de PPGAs com quantidade reduzida de componentes curriculares que precisaram ser complementados; 6 . Programas com mais de 100 disciplinas cadastradas tiveram redução para no máximo 100 unidades. As medidas adotadas para a eliminação foram: a) disciplinas com o mesmo conteúdo em mais de um idioma, sendo mantida a nomenclatura em português; b) disciplinas com denominações redundantes e/ ou complementares de mesma carga horária foram reduzidas para apenas uma; c) todos os critérios dos passos anteriores também foram aplicados a esses programas.

A realização da pesquisa demandou alguns passos, entre a coleta, tratamento, classificação e análise dos dados, que consistiram das seguintes etapas:

Coleta das disciplinas dos 37 programas na Plataforma Sucupira

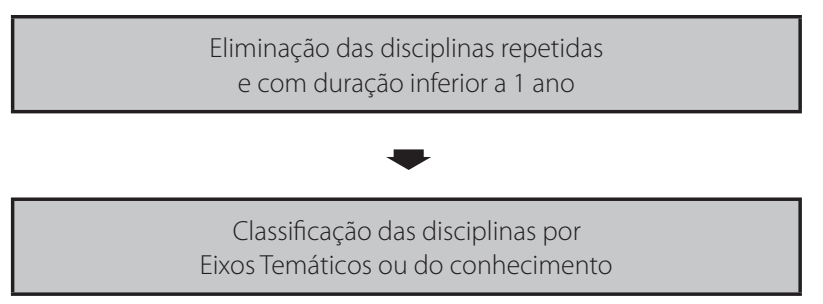

Contagem das unidades do conjunto de componentes de cada eixo

Classificação segundo as características curriculares dos PPGAs

Figura 2 Etapas para coleta e tratamento dos dados

Fonte: Dados da pesquisa
Após a realização da coleta e organização dos dados em planilha eletrônica, foi realizada a classificação das disciplinas por eixos, que correspondem às áreas do conhecimento da Administração.

A classificação das disciplinas em eixos obedeceu a alguns critérios pré-determinados, tais como:

a) a classificação seguiu um padrão, como por exemplo, Administração de Marketing ou Comportamento do Consumidor foram classificados em "Marketing”, assim como Gestão de Pessoas, Comportamento Humano, Aprendizagem organizacional ou estudos organizacionais foram classificados como "Organizações" e assim por diante.

b) em alguns casos, em que as matrizes são interdisciplinares houve maior dificuldade para classificação. Um dos exemplos a serem citados pode ser a denominação: "Da produção ao consumo: competitividade, inovação e sustentabilidade". Nesse caso, por haver a compreensão de que a disciplina se encaixa em três eixos, foi classificada em Estratégia, Inovação e Sustentabilidade. Todavia, esses casos foram raros se comparados com todas as classificações realizadas. c) Nos casos de disciplinas complexas, em que houve dificuldade de classificação, foram consultados os "dados da disciplina", localizados ao lado direito da linha correspondente à disciplina na Plataforma Sucupira, (CAPES, 2017a).

O critério adotado para contagem da quantidade de disciplinas distribuídas entre os eixos se respaldou nos seguintes parâmetros: d1) Os eixos que registraram as quantidades mais expressivas receberam peso 5 . Os eixos que atingiram $75 \%$ da quantidade correspondente ao $1^{\circ}$ eixo receberam peso 4 . Com $50 \%$ do 1 - eixo receberam peso 3 , com $30 \%$ receberam peso 2 e com $20 \%$ da quantidade de disciplinas do $1^{\circ}$ eixo receberam peso 1 , sendo que o limite mínimo para consideração dos conjuntos de disciplinas na formação de um eixo seria da ordem de 05 componentes (para PPGAs de matriz ampla). d2) Quanto ao último critério houve a reconsideração dos valores para alguns PPGAs, no caso, aqueles que possuem matriz reduzida em que a quantidade de 
disciplinas cadastradas não se mostrou significativa para uma análise consistente. Alguns exemplos são os programas que apresentaram classificação em apenas dois eixos, como UECE, UFSM e outros PPGAs que ficaram classificados em 3 eixos mais genéricos, como PUC/SP, UPM, UNIVALI e UNIGRANRIO. Nesses casos, foram realizadas revisões cuidadosas, chegando-se a considerar como significativa a quantidade de três disciplinas por eixo.

\subsection{Métodos}

Os dados foram analisados por meio de estatística descritiva e análise de agrupamentos. Quanto às análises estatísticas fez-se uso das técnicas referentes à média, mediana, moda, variância e desvio-padrão, calculados em planilha eletrônica. Quanto à análise de agrupamentos, o método utilizado é descrito a seguir.

\subsubsection{Método Co-plot}

O método utilizado para tratamento dos dados se trata de uma representação bidimensional de um conjunto de dados e recebe o nome de Co-plot. Foi adaptado do estudo de Segev et al. (1999), que estudaram os 25 melhores cursos americanos de MBA em Administração. O mesmo método foi aplicado em vários estudos, incluindo o estudo dos MBAs latino-americanos, dos autores Scafuto et al. (2017). Alguns exemplos de outros estudos, são: diferenças socioeconômicas entre cidades (MINDALI ET AL., 2004; RAVEH, 2000); fusões e aquisições (WEBER, ET AL.,1996); evolução da tecnologia informática (GILADI ET AL. 1996), análise de desempenho do sistema bancário grego (RAVEH, 2000); identificação de similaridades estruturais em instituições de ensino superior de programas de pós-graduações (BACKES, SERRA, ZAROUR NETO. 2018), dentre outros.

O método Co-plot (TALBY; FEITELSON; RA$\mathrm{VEH}, 2007)$ oferece a vantagem da apresentação de um conjunto de dados no plano bidimensional, por meio da visualização simultânea de variáveis e observações no mesmo gráfico. O método é uma variação da análise de regressão e consiste de uma matriz derivada de $\mathrm{Y}=\mathrm{n} \mathrm{x}$, sendo que $\mathrm{n}=37$ (PPGAs) e $\mathrm{p}=23$ (disciplinas), centradas no mesmo eixo e mesma origem. As etapas para execução são quatro, conforme a seguir:

A primeira etapa é a normalização das variáveis, por meio da obtenção da média igual a zero e variância igual a 1 . A segunda etapa consiste na diferenciação dos pares de observações pela métrica de Minkowski, de modo a ser possível calcular a distância entre cada par de observação, sendo representada pela equação:

$$
S_{i k}\left[\sum_{j=1}^{p}\left|Z_{i j}-Z_{i j}\right|^{r}\right]^{1 / r} \geq 0,(1 \leq i, k \leq n ; r \geq 1)
$$

A partir das coordenadas $2_{n}\left(X_{1 i}, X_{2 i}\right) i=1, \ldots$, n, em que cada linha $Z_{i}=\left(Z_{i 1}, \ldots, Z_{\text {ip }}\right)$ é representada por meio de um ponto $\left(X_{1 i}, X_{2 i}\right)$, a terceira etapa é a transformação de valores similares em distancias que permitirão o mapeamento da matriz no espaço Euclidiano, por meio de Escalonamento Multidimensional (MDS). A última etapa exibe o arranjo gráfico entre observações e variáveis, considerando que as variáveis j são calculadas individualmente e projetadas por meio de setas que insurgem do núcleo de gravidade dos pontos apontando suas correlações.

\section{RESULTADOS}

Os resultados são divididos em três seções. $\mathrm{Na}$ primeira, por meio do uso de estatística descritiva, realizamos a caracterização dos PPGAs de acordo com as matrizes curriculares. Na segunda etapa apresentamos a formação dos grupos a partir do uso do método Co-plot e na terceira seção tecemos as discussões em torno dos resultados encontrados.

\subsection{Caracterização dos PPGAs de acordo com as matrizes curriculares}

Os PPGAs apresentam heterogeneidade quanto ao tamanho da matriz, interdisciplinaridade, diversidade e complexidade. A seguir são apresentadas as principais características dos PPGAs de acordo com os resultados da pesquisa, a começar pela dimensão da matriz, conforme Figura 3, sendo seguidos pela média e mediana do conjunto de dados. 


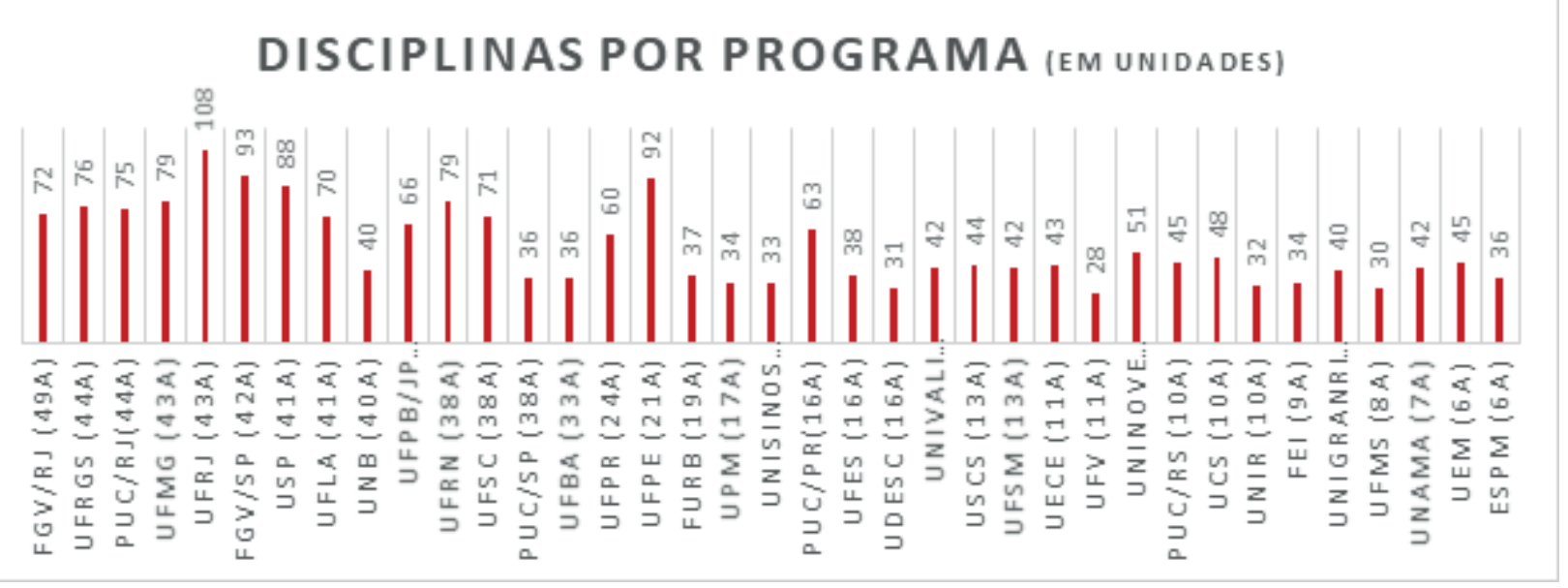

Figura 3 Quantidade de componentes curriculares por PPGA.

Fonte: dados da pesquisa (2017).

A média da quantidade de disciplinas adotadas pelos programas, isto é, a soma de todos os valores divididos pela quantidade de observações, é igual a 53,5. A variância do conjunto de dados se mostrou elevada $(461,30)$ e indica que os tamanhos dos currículos estão dispersos em relação à média. O desvio- padrão, raiz quadrada da variância, é igual a 21,5. As medidas deixam evidente a heterogeneidade do grupo de dados. A moda, ou quantidade mais frequente de disciplinas nas matrizes curriculares dos programas, apresentou dois valores comuns, 42 e $36 \mathrm{em}$ seis dos programas pesquisados, sendo três programas para cada uma das quantidades encontradas. Quanto à mediana, ou valor que divide o conjunto de dados entre metade superior e inferior, esta é igual a 44 .

Conforme Figura 3, cuja idade do PPGA está exposta ao lado da nomenclatura da instituição, verificou-se que há tendência de matrizes mais enxutas entre os programas mais jovens e matrizes mais amplas e diversificadas entre os mais antigos. Nesse estudo, consideram-se programas antigos aqueles que possuem idade superior a 30 anos, em razão da mudança do padrão de avaliação da CAPES, que passou por reestruturação em 1990 e a partir de então tornou a regulamentação sobre os PPGs mais intensa. Todavia, nem todo curso antigo tem a matriz extensa, uma das exceções são os programas da UNB, PUC/ SP e UFBA. Ao mesmo tempo em que há casos como o da UFPE, PUC/PR e UFPR dentre os PPGAs mais jovens que possuem matrizes curriculares densas. Esses programas, apesar de jovens, apresentam quan- tidade de disciplinas superior à média do conjunto de dados $(53,5)$.

A polarização em torno das quantidades de disciplinas não significa maior concentração ou maior amplitude em relação à diversidade de temas. Essa não é uma regra. Nem toda matriz enxuta é concentrada. Há casos de matrizes reduzidas e com disciplinas voltadas para as mais diversas áreas, chegando a 10 diferentes categorias ou eixos disciplinares, como é o caso da UNB, FURB, UPM, UFES, UDESC, UNIVALI, USCS, UFSM, UECE, UNIR, UNIGRANRIO, UNAMA e UEM (Figura 10). Em compensação há matrizes centradas, servindo como exemplo os programas da UFV e PUC/RS, com menos de 7 eixos disciplinares cada um.

Há matrizes com alto nível de interdisciplinaridade, como é o caso da UFRGS, UFPE, FGV/ SP, UFLA, UFSC, PUC/SP, UFES, UDESC, USCS, UFSM, UCS, UNIR, FEI, UNAMA e UEM, mas se comparados ao total de programas estudados, ainda representam uma parcela reduzida. Esse é um dos critérios valorizados pela CAPES nas avaliações, que além da inovação, incentiva a interdisciplinaridade nas propostas dos programas (CAPES, 2016). Existe também matrizes com alto nível de complexidade na nomenclatura de seus componentes curriculares, os melhores exemplos são as matrizes curriculares da FGV/RJ e PUC/PR, entre outros PPGAs.

Dos 37 programas pesquisados, 21 apresentaram grau elevado de similaridade com outros PPGAs. Destacaram-se como programas com o maior número de 
relações com os demais, por ordem de observações, os pertencentes à USP, FGV/SP, UFRJ e PUC-RIO (Figuras 6, 7, 8 e 9), que podem ter influenciado a construção da matriz de vários programas ou ter recebido alguma influência. Programas mais antigos e tradicionais, como os da UFGRS, FGV/RJ, UFMG, dentre outros, poderiam não só ter se espelhado na matriz da USP e FGV/SP, os PPGAs com maior similitude, como ter servido de modelo para elas. Já as relações com os programas mais jovens podem significar inspiração desses nas referidas instituições, pois segundo Dimaggio e Powell (1983), as organizações mais jovens e menos legitimadas podem decidir se assemelhar às organizações mais bem-sucedidas para aumentar as chances de legitimação.

No entanto, as matrizes curriculares podem ter sido alteradas pelos PPGAs ao longo do tempo, e nesse caso, a ordem cronológica não teria relevância, embora todo programa preserve suas competências essenciais ao atualizar a matriz curricular. As core competences são aquelas competências, ou aquele conjunto de conhecimento, habilidades, tecnologias, sistemas físicos e gerenciais, difíceis de ser copiados, que geram valor percebido pela clientela e asseguram vantagem competitiva à organização (PRAHALAD; HAMEL, 1990). Mesmo que os PPGAs possam alterar suas matrizes a qualquer tempo, o completo alinhamento com a proposta do programa não permite flexibilidade completa.

A análise feita até aqui é simplificada e buscou apenas identificar a similaridade das matrizes a partir da presença ou ausência do eixo na matriz disciplinar. Até esse momento não foram verificados os pesos de cada eixo para o programa, o que pode gerar diferenciação ao tratar os dados com ferramentas estatísticas mais avançadas. O peso está relacionado à quantidade de disciplinas associadas a um determinado eixo temático.

\subsection{Formação dos grupos a partir do uso do método Co-plot a partir dos PPGAs}

Uma das vantagens do método Co-plot, é que além de permitir a análise de variáveis individuais, possibilita a compreensão das correlações entre todas as variáveis de uma só vez, ao mesmo tempo em que consegue definir conjuntos de variáveis e as relações entre eles. Verificou-se que o coeficiente de alienação obtido para o conjunto de variáveis foi igual a 0,23 e o correlação média entre as variáveis foi igual a 0,45 (Figura 4), scores considerados bons, uma vez que os valores ideais é que o coeficiente de alienação (entre 0 e 1) esteja o mais próximo possível de zero (JOHNSON, 1997) e o coeficiente de correlação (entre -1 e 1) esteja o mais distante possível de zero (FIGUEIREDO FILHO; JUNIOR, 2010). Conforme esperado, não se verificou correlação elevada entre as disciplinas, já que uma não deve interferir sobre a outra, pois representam eixos temáticos discriminantes.

Os programas formaram quatro grupos estratégicos de diferentes dimensões e coesão. O grupo mais numeroso e mais coeso é formado por quinze componentes e abarca os PPGAs das instituições UPM, UFRN, UFSM, UNIVALI, UNIGRANRIO, UNISINOS, UNINOVE, FURB, UNIR, PUC-RIO, PUC/PR, PUC/RS, PUC/SP, UFPR e UFPB/JP. O que esses programas têm em comum é que a maior parte deles possuem conceito 5, sendo considerados PPGAs de referência nacional. Apenas quatro deles possuem nota 4. Com exceção dos PPGAs da UFRN, PUC-RIO, PUC/SP, UFPB/JP e UFPR, todos os programas possuem menos de 20 anos. Portanto, as características mais homogêneas indicam que o Grupo 1 é formado por organizações jovens e de alto desempenho. Os eixos que unem o grupo por unanimidade é Estratégia, Métodos e Organizações (todos com peso acima de 3). O último eixo só não está presente nas matrizes da PUC/PR e PUC/RS.

$\mathrm{O}$ segundo grupo mais numeroso possui oito integrantes, que são bem alinhados em torno do eixo referente à "Administração Pública, Sociedade e Economia”. Os PPGAs componentes são: FGV/RJ, UNB, UFBA, UFES, UFV, UFLA, UDESC, UECE, dos quais FGV/RJ, UNB e UFLA possuem mais de 40 anos e UFBA, 34. Os demais PPGAs (UFES, UFV, UDESC, UECE) possuem menos de 16 anos. Os conceitos dos programas são bastante variados, sendo FGV/RJ (6), UNB (5), UFBA (5), UFLA (5), UFES (4), UFV (4), UDESC (4), UECE (4). Se trata, portanto, de um grupo bastante heterogêneo quanto à estrutura, que possui como direcionador principal as discussões voltadas para o nível macro, englobando temas referentes à Gestão Pública, Política, Sociedade e Economia. 


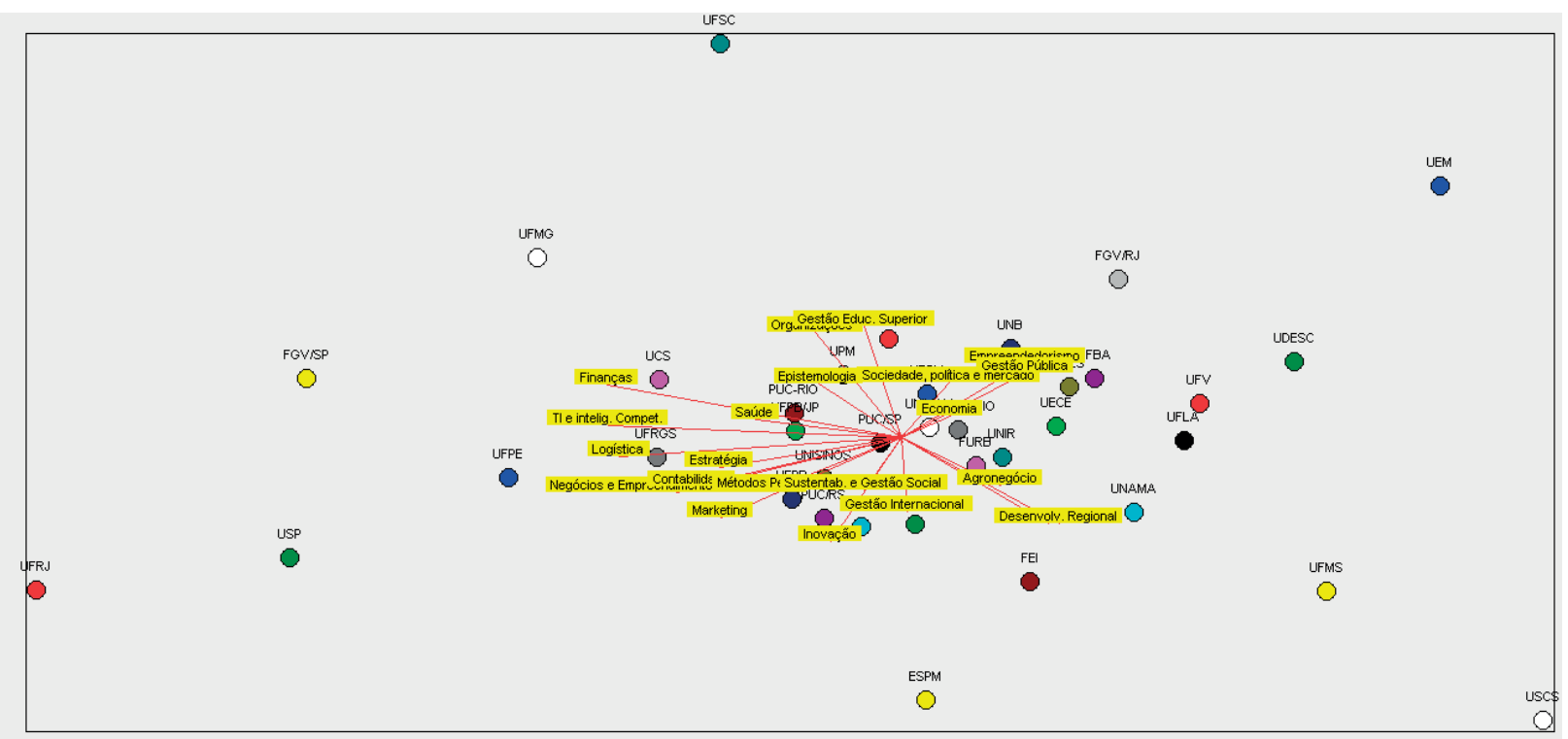

Iot's coefficient of alienation is 0.23 and average of correlations is 0.45 .

Figura 4 Correlações entre as disciplinas e sua relação com cada PPGA

Fonte: dados da pesquisa (2017).

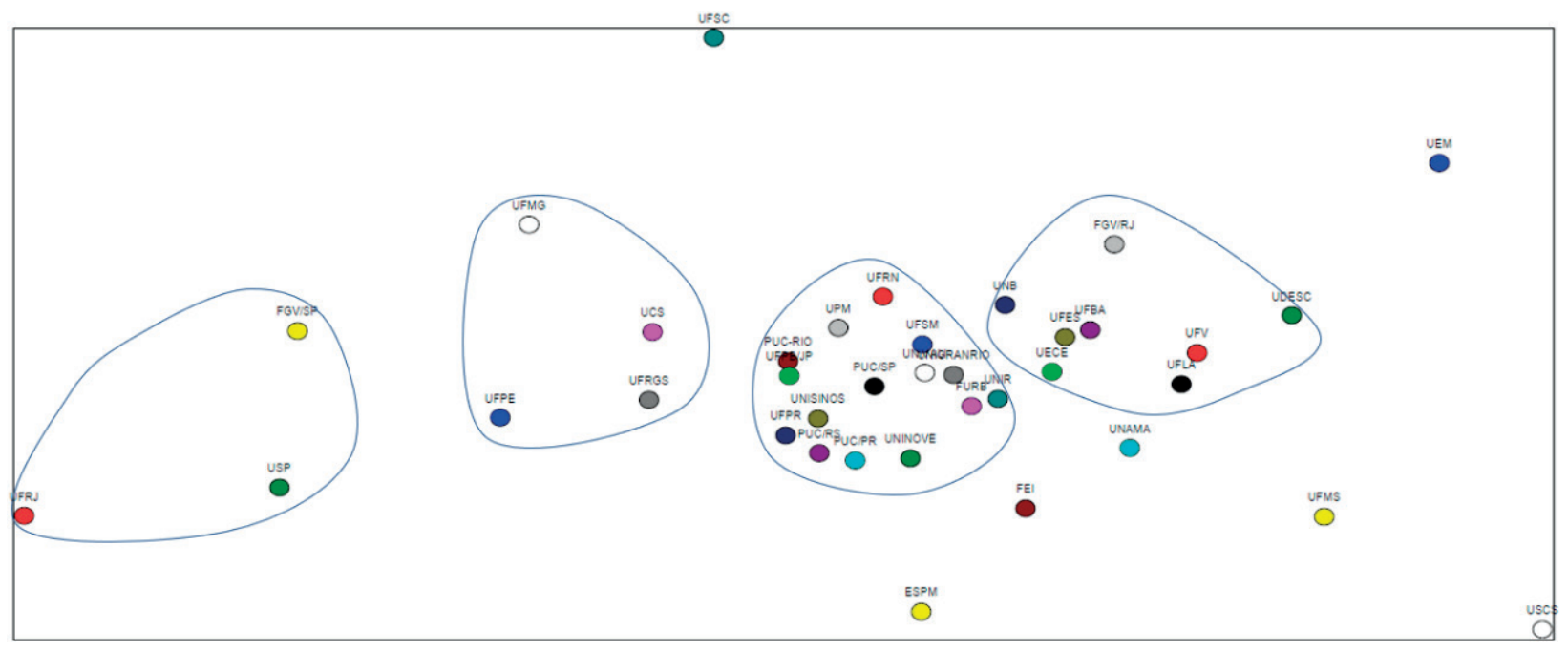

Figura 5 Grupos estratégicos formados pelos PPGAs

Fonte: dados da pesquisa (2017).

O terceiro grupo, um pouco mais disperso e menos numeroso, inclui quatro membros, UFMG, UFRGS, UFPE, UCS, sendo UFRGS e UFMG programas com mais de 40 anos, UFPE possui 23 anos e UCS é um PPGA de apenas 12 anos. Os conceitos variam de 4 a 6, sendo UFMG (6), UFRGS (5), UFPE (4), UCS (4). São programas que possuem em sua matriz curricular eixos tradicionais e um eixo específico voltado para "Tecnologia da Informação e Inteligência Competitiva”, exceto UFMG para esse último. Em compensação UFMG possui 5 eixos em comum com UFRGS e UFPE, sendo "Organizações", "Marketing", "Métodos", "Estratégia" e "Finanças". Os eixos "Sustentabilidade", "Inovação" e "Logística" também são comuns em pares desses PPGAs.

O quarto grupo abarca os PPGAs da FGV/SP, USP e UFRJ, todos com mais de 40 anos e com conceitos máximos, exceto UFRJ (4). Os PPGAs da USP e da FGV/SP possuem 7 eixos em comum, ao passo que USP e UFRJ possuem 9 eixos em comum. Esta é 
a quantidade mais expressiva dentre todos os eixos comuns observados entre os programas e significa que o nível de similaridade é extremamente elevado, pois dos 10 eixos que os dois PPGAs possuem, 9 são semelhantes. A mesma proporção se verifica no PPGA da FGV/SP, sendo que dos 8 eixos do programa 7 são semelhantes aos da USP. O fato de não formarem um grupo tão coeso no plano bidimensional está relacionado à quantidade elevada de eixos, que elevam seus coeficientes em relação à média geral de todos os PPGAs, além de que nem todos os eixos tem o mesmo peso. A mensuração do peso de cada eixo gera diferenciação em relação à análise puramente atrelada ao fato de possuir um eixo ou não.

Além dos grupos formados, há sete PPGAs que não se aglomeram com nenhum outro, sendo considerados outliers, são eles, UFSC, UEM, UFMS, USCS, UNAMA, FEI e ESPM. Todos esses programas possuem menos de 15 anos, com exceção da UFSC, que possui 40 anos, e todos possuem conceito 4, exceto USCS (5). Esses PPGAs não se aglomeram porque possuíam eixos únicos em relação aos demais, por exemplo, o PPGA da UFSC possui um eixo exclusivo voltado para a Gestão da Educação Superior e outro eixo que poucos programas possuem direcionado para o Desenvolvimento Sustentável.

O PPGA da UEM possui um eixo exclusivo orientado para o Empreendedorismo, isso não quer dizer que outros programas não abordem essa temática, a questão é que um eixo é formado a partir de várias disciplinas comuns relacionadas aquele tema, ao passo que em programas que possuam poucas disciplinas referente ao tema não se configure como um eixo. Outro eixo que a UEM possui que poucos programas abordam é "Sociedade, política e mercado". O PPGA da UFMS, por sua vez, possui uma vocação muito forte para o agronegócio, que é única entre os programas, além de possuir um eixo pouco comum voltado para "Sustentabilidade e Gestão Social". O PPGA da USCS possui um eixo exclusivo voltado para "Redes" e um eixo que só o PPGA da UNAMA também possui, que é Desenvolvimento Regional. A UNAMA, além do último eixo citado possui um eixo direcionado para Sustentabilidade e Gestão Social, o que a diferencia dos demais PPGAs pelo arranjo entre eixos raros.
A FEI é constituída por eixos comuns em outros programas, mas raros, e assim como a UNAMA, sua diferenciação está na combinação dos eixos, já que Inovação, Marketing e Sustentabilidade e Gestão Social não é comum nos outros PPGAs. Embora USP e UFRGS possuam eixos em comum, a força da FEI que a diferencia dos demais é o peso maior concentrado no eixo Sustentabilidade e Gestão Social. A ESPM possui um eixo exclusivo orientado para Gestão Internacional. Embora outros PPGAs tenham Negócios e Empreendimentos Internacionais, a ESPM tem a vocação do programa toda envolvida com a temática internacional, de modo que todas as disciplinas do programa se voltam para o contexto de internacionalização.

Nessa composição não surpreende verificar programas jovens com matriz diferenciada e focos em eixos exclusivos porque nos últimos anos houve um esforço da CAPES no sentido de induzir os PPGAs a incorporarem temáticas inovadoras em suas propostas de novos cursos. Sobre isso, Dacin (1997) explica que é comum as organizações moldarem seu comportamento de acordo com as regras e normas do período de fundação. Contudo, nesse cenário destaca-se o PPGA da UFSC por ser um programa bastante antigo e possuir uma matriz diferenciada dos demais, em especial dos contemporâneos, o que contraria a lógica institucional. Todavia, o que se observa é que há alto grau de similaridade entre as matrizes curriculares dos PPGAs mais antigos, conforme demonstrado nas Figuras 6, 7, 8 e 9.

Nesse caso, é provável que a influência americana sobre a Administração (DOS SANTOS; AZEVEDO, 2009, ISHIKAWA, 2009), conduziram os programas mais antigos a adotar estruturas curriculares semelhantes.

\subsection{Discussão dos Resultados}

A discussão deste estudo empírico pode ser sintetizada em três pontos. O primeiro é que o campo organizacional apresenta indícios de isomorfismo mimético, confirmando a abordagem teórica adotada e corroborando com os resultados empíricos em outros países. Isso significa que por razões estratégicas ou mediante as incertezas criadas pelo ambiente que permeia a educação superior, e em especial no nível 


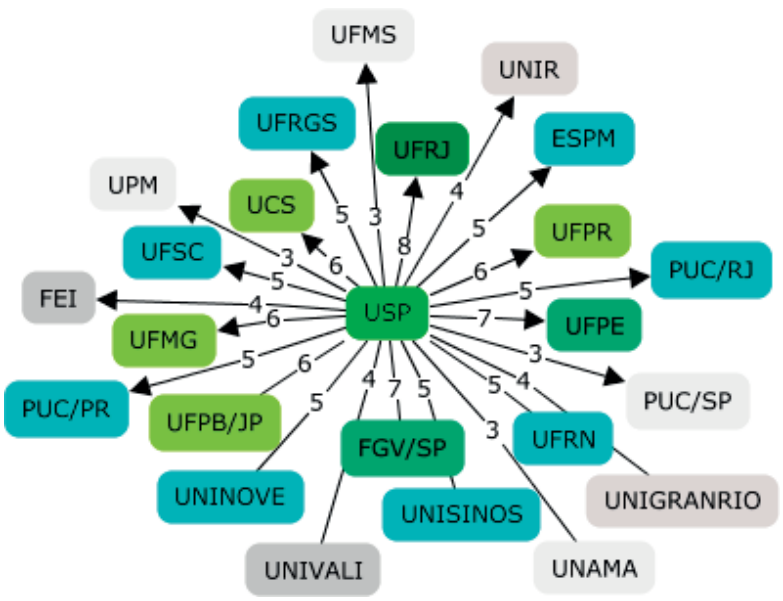

Figura 6 Relações da USP com outros PPGAs

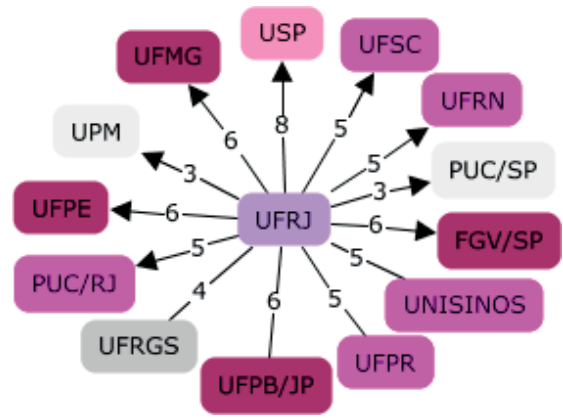

Figura 8 Relações da UFRJ com outros PPGAs

stricto sensu, onde se concentra a maior produção científica relevante, o isomorfismo mimético se faz presente. O recorte temporal é um fator importante no cenário acadêmico, pois a regulamentação mais intensa se iniciou por volta dos anos 1970 nos Estados Unidos e se espalhou por mais de metade do globo nos anos seguintes, criando uma movimentação global de disseminação de regimes de garantia da qualidade (CROUCHER; WOELERT, 2016; ISHIKAWA, 2009, LARRÁN, ET AL., 2015; MIGUEL, ET AL., 2021).

Para impulsionar a inserção das instituições nacionais no cenário internacional de ensino e pesquisa, os governos implantaram sistemas de certificação e conformidade por meio da validação de padrões de qualidade (CROUCHER; WOELERT, 2016; JARVIS, 2014), que geraram aumento de pressões combinadas com variáveis ambientais incertas e produziram sobre as instituições de ensino superior tendências de convergência quanto à estrutura (CROUCHER; WOELERT, 2016). No Brasil não foi diferente. Por meio da CAPES, o país ingressou na lógica global. Ao

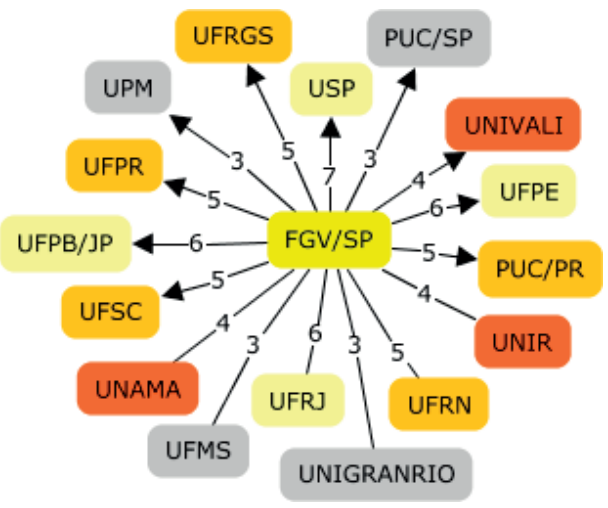

Figura 7 Relações FGV/SP com PPGAs

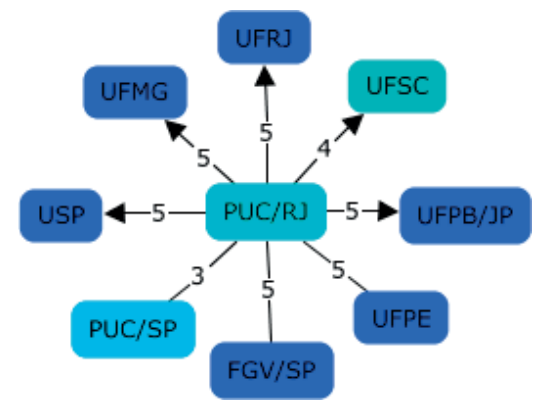

Figura 9 Relações PUC/RIO com PPGAs

buscar o reconhecimento da sociedade e das instituições de avaliação e acreditação do ensino superior, os programas de pós-graduação moveram esforços para moldar a sua estrutura de acordo com as instituições reconhecidamente legitimadas.

O segundo ponto a ser destacado é que os dados empíricos demonstraram a prática do espelhamento entre os programas, principalmente pelo grau de similaridade entre as matrizes daqueles mais tradicionais e legitimados para os demais. Por meio da identificação do conjunto de eixos temáticos semelhantes foi possível identificar as instituições mais inspiradoras. Essas instituições podem pertencer a uma elite do sistema nacional de educação superior, e que por múltiplas razões inspiram as demais. Todavia, essas IES certamente se inspiram em instituições internacionais conhecidas por constarem em posições elevadas dos rankings mundiais de avaliação, sendo essa uma tendência das instituições de ensino superior em todo o mundo (ANAFINOVA, 2020; ISHIKAWA, 2008, GANGA, ET AL. 2017, JARVIS, 2014, MARINI, 2020; PAPADIMITRIOU, ET AL. 2010). 
Tem-se a noção de que o sistema de avaliação ao atribuir notas, conceitos ou certificações, também estabelece um ranking que divide as IES em classes, ao definir as mais legitimadas no topo, as que apresentam nível intermediário de desempenho no meio, e as que vão ocupar as posições da base da pirâmide como as que obtiveram menor nível de desempenho. Nesse caso, é importante ressaltar que o conceito é um bem simbólico, mas que tem implicações sobre a percepção das pessoas, tais como a tendência dos membros de internalizar as pressões, e se tornarem autodisciplinadores, além de que a internalização pode ser fomentada pela ansiedade que os rankings produzem, ou pelo fascínio para com os administradores que conseguem manipulá-los ou ainda pela resistência que eles provocam (Sauder, Espeland, 2009).

O impacto do posicionamento de uma instituição em um ranking não afeta apenas a forma como as pessoas assimilam o conceito recebido, mas há reflexos sobre a credibilidade perante à sociedade $\mathrm{e}$ diante da capacidade de captação de recursos (DIAS SOBRINHO, 2003) junto às agências de financiamento do ensino superior e as agências de fomento à pesquisa. Esse fator pode levar muitas instituições a colocarem as normas regulatórias acima dos próprios objetivos estratégicos (MACCARI ET AL., 2014; PEDERSEN ET AL. 2013, SPAGNOLO; CALHAU, 2002). Isso significa que além das questões subjetivas envolvidas com a legitimidade, há implicações práticas e reais sobre a gestão organizacional e podem envolver a motivação da equipe docentes e discente da instituição.

É fato que há um aumento da competitividade na educação superior de um mercado de pesquisa cada vez mais global (HAMMARFELT; FREDRIK, 2015), todavia é importante ressaltar que esse dinamismo para o avanço internacional da ciência e tecnologia também permitiu o estabelecimento de parcerias, cooperação e colaboração entre as instituições, o que gerou benefícios científicos, e se trata de um fato importante a ser reconhecido, entretanto, não se pode perder de vista que há o risco de domínio de modelos poderosos que possam vir a transformar identidades e afetar hierarquias internas, tanto dentro do indivíduo e instituições, como em todo o sistema nacional de ensino superior (ISHIKAWA, 2008; VOLPATO; FREITAS, 2003).
Especificamente, quanto às influências internacionais sobre o contexto científico brasileiro, há incentivo do órgão regulador nacional - CAPES para que as instituições formem redes de pesquisa e estabeleçam parcerias com instituições estrangeiras. A CAPES tem como objetivo a manutenção de um sistema de avaliação aprimorado para a atingir um padrão nacional de excelência acadêmica (CAPES, 2008), e assim, certamente atuará como incentivadora para que os programas busquem fontes de inspiração nos modelos legitimados para a construção das propostas, principalmente modelos internacionais, que combine os interesses da academia científica brasileira com os temas de interesse de pesquisa mundial. A valorização da perspectiva de internacionalização nos quesitos de avaliação atuais são um forte indicador desse propósito.

O terceiro ponto a ser destacado nesse estudo é a contribuição teórica proposta no início do artigo. Tendo em vista, os vários estudos realizados sobre a identificação de indícios de isomorfismo mimético e os efeitos sobre as instituições de ensino superior, não foi encontrado estudos na literatura que tenham testado de forma empírica a relação entre a adoção de estruturas isomórficas e o desempenho correspondente. Os achados deste estudo lançam luz sobre o impulsionamento das agências governamentais ao instigar as instituições a adotar práticas e estruturas isomórficas e os resultados alcançados de fato. Isso significa que há uma diferença entre expectativa e concretização.

$\mathrm{O}$ fato de terem sido identificados agrupamentos de matrizes curriculares semelhantes não significa apenas que os PPGAs possuam disciplinas que formam eixos temáticos similares, mas que existe uma estrutura correlata para dar suporte a esses componentes curriculares. A estrutura correspondente também é um quesito de avaliação do órgão regulador que estabelece que as disciplinas devem estar alinhadas com as linhas de pesquisa e com as áreas de concentração dos programas (CAPES, 2016). Isso significa que há um conjunto de recursos alinhados, tais como corpo docente com as competências relacionadas, recursos físicos e tecnológicos para o desenvolvimento das atividades, além de uma rede de pesquisa interligada. Portanto, a matriz curricular 
representa uma gama de recursos associados que podem tornar evidente a presença do isomorfismo.

Todavia, o fato de assemelhar a estrutura às instituições mais legitimadas não garante resultados semelhantes. Entre a expectativa e o alcance das metas há um percurso e uma variável mediadora muito importante, a gestão dos recursos e engajamento das equipes dentro das limitações do conjunto de recursos disponíveis. Como verificado nos resultados do estudo empírico, dentro de grupos com estruturas isomórficas há diversidade de conceitos obtidos junto ao órgão avaliador, o que demonstra que similaridade estrutural não corresponde a desempenho equivalente, o que leva à proposição de que isomorfismo não possui correlação com gestão estratégica.

Embora tenha sido constatada a presença de isomorfismo entre as instituições incluídas na pesquisa empírica, a possibilidade de uniformização total das estruturas e procedimentos de funcionamento são pouco prováveis. As similaridades isomórficas tem um limite de avanço e são dependentes do conjunto de recursos operacionais e estruturais. Por mais uniformes que sejam as estruturas, os resultados gerados dificilmente se equalizam, de modo que cada organização possui um conjunto de recursos únicos (OLIVER, 1997; CRUBELATTE ET AL. 2005) que dificilmente conseguem ser replicados. O desempenho obtido pode ser aproximado, mas não idêntico. Portanto, mover esforços para manter estruturas isomórficas não implica em desempenho equivalente.

\section{CONCLUSÕES}

Com vistas a suprir a lacuna empírica e colaborar com a discussão sobre as práticas voluntárias de assemelhamento de estruturas decorrentes das incertezas presentes em ambientes regulamentados, nesse estudo procurou-se identificar a presença de isomorfismo mimético a partir das similaridades estruturais das matrizes curriculares dos PPGAs, ao mesmo tempo em que se buscou verificar se o mimetismo contribui para o desempenho similar no ranking de acreditação do ensino superior. A partir da identificação de quatro grupos, foram identificadas similaridades estruturais e de acordo com a distribuição dos pontos no plano bidimensional, foi possível verificar a postura diferenciada de cada grupo formado, ao tornar evidente a tendência de cada conjunto de instituições que assemelham suas estruturas entre si.

Os resultados da pesquisa permitem concluir que os rankings de avaliação do ensino superior conduzem a comportamentos isomórficos intergrupais. Constatou-se, porém, que a participação em um grupo isomórfico não significa desempenho semelhante a todos os componentes. Esse achado suscitou uma série de reflexões a respeito da Teoria neo-institucionalista isomórfica, quanto à impossibilidade de se obter os resultados homogêneos a partir do espelhamento de estruturas e procedimentos das organizações de referência. A proposição principal dos achados do estudo empírico é que não se pode obter desempenho equivalente porque o conjunto de recursos, cultura organizacional e core competences obtido e desenvolvido pelas instituições dificilmente poderão ser desenvolvidos a ponto de ser tornarem idênticos de uma organização para a outra. Para compreender esse universo de forma integral e não apenas com base na análise das relações superficiais interorganizacionais, recomenda-se lançar mão sobre uma visão que considera as características internas da organização e a observe como um agente ativo no processo, capaz de ser induzido a certos comportamentos, mas também influenciar o campo organizacional ao qual pertence.

Quanto ao papel do órgão regulador brasileiro é esperado que possa promover o desenvolvimento do campo organizacional como um todo. É necessária atenção para não incorrer no risco de privilegiar as instituições de ensino e pesquisa legitimadas, em detrimento das menos reconhecidas, que podem vir a operar com financiamento reduzido e dificuldades crescentes de ascensão a patamares acadêmico-científicos mais elevados. O órgão público regulador, que desempenha também o papel de financiador da pesquisa, possui duas importantes funções de fomento à pesquisa nacional. Do seu planejamento claro e conciso e estabelecimento de normas estáveis depende o desenvolvimento da ciência brasileira.

As limitações do estudo se restringem à primeira parte da metodologia, esmerosa e com algumas etapas onde foi necessário o uso da subjetividade, como por exemplo, a classificação das disciplinas e categoriza- 
ção dos eixos, todavia, essa etapa foi necessária pelo fato das análises puramente quantitativas deixarem a desejar quanto ao critério da subjetividade mínima, que permite a exploração mais profunda do meio pesquisado e o estabelecimento de relações que forneçam uma explicação sobre os fatos ou fenômenos (QUIVY; CAMPENHOUDT, 1998).

As sugestões para estudos mais profundos se referem aos PPGAs, segundo os tipos de perfis apresentados para elucidar alguns pontos importantes, como por exemplo, os fatores que levam um programa a decidir assemelhar sua estrutura a outro e os fatores que o impedem de obter os mesmos resultados. Essas discussões em profundidade contribuíriam com o campo teórico institucional e com a prática gerencial dos programas de pós-graduação.

\section{REFERÊNCIAS}

ALMEIDA, K. K. N. DE; CAlladO, A. L. C. Indicadores de desempenho ambiental e social de empresas do setor de energia elétrica brasileiro: uma análise realizada a partir da ótica da Teoria Institucional. Revista de Gestão, Finanças e Contabilidade, v.7, n. 1, p. 222-239, 2017.

BACKES, D.; SERRA, F.; ZAROUR NETO, F. Identifying structural similarities between stricto sensu post-graduation programs in management regarding the strategy tripod. REGE Revista de Gestão. v. 25, n. 3 (Oct. 2018), p. 303-320, 2018.

BURNS, L. R.; WHOLEY, D. R. Adoption and abandonment of matrix management programs: Effects of organizational characteristics and interorganizational networks. Academy of management journal, v.36, n.1, p.106-138, 1993.

CAPES. História e missão. 17 Junho 2008. Recuperado em 21 fevereiro, 2018, de http://www. capes.gov.br/historia-e-missao

CAPES. Sobre avaliação de cursos. Recuperado em 09 Julho, 2017, de http://www.capes.gov.br/acessoainformacao/perguntas-frequentes/avaliacao-da-pos-graduacao/7421,-sobre-avaliacao-de-cursos. 2015.
CAPES. Orientações para apcn-2016. Recuperado em 20 Julho, 2017, de https://www.capes.gov.br/ images/documentos/Criterios_apcn_2016/Criterios_ APCN_Administracao.pdf

CAPES. Portaria No 59, de 21 de março de 2017. Regulamento da Avaliação Quadrienal. Recuperado em 19 Junho, 2017, de http://capes.gov.br/images/ stories/download/avaliacao/27032017-Portaria-59-21-03-2017-Regulamento-da-Avaliacao-Quadrienal.pdf

CAPES. Coleta Capes - Disciplinas. Recuperado em 19 Fevereiro, 2017a, de https://sucupira.capes.gov.br/ sucupira/public/consultas/coleta/disciplina/listaDisciplina.jsf;jsessionid=VyKGEDdY9EGrj5vgsYcydDsS. sucupira-203.

CROUCHER, G.; WOELERT, P. Institutional isomorphism and the creation of the unified national system of higher education in Australia: An empirical analysis. Higher Education, v.71, n. 4, p. 439-453, 2016.

DACIN, M. Isomorphism in context: the power and prescription of institutional norms. Academy of Management Journal, v. 40, p.1, p. 46-81, 1997.

DA SILVA, J. R. C., MUSSI, C. C., CASAGRANDE, J. L., DE LIMA, M. A. A incidência dos mecanismos isomórficos nos processos de autoavaliação institucional. Navus-Revista de Gestão e Tecnologia, v. 9, n.3, p. 173-186, 2019.

DIAS SOBRINHO, J. Avaliação da educação superior regulação e emancipação. Avaliação, v.8, n. 2, p.31- 47, 2003.

DIMAGGIO, P.; POWELL, W. The iron cage revisited: institutional isomorphism and collective rationality in organizational fields. American Sociologic Review, v. 48, p. 2, p.147-160, 1983. 
DOS SANTOS, A. L. F.; DE AZEVEDO, J. M. L. A pós-graduação no Brasil, a pesquisa em educação e os estudos sobre a política educacional: os contornos da constituição de um campo acadêmico. Revista Brasileira de Educação, v.14, n. 42, p. 534550, 2009.

FIGUEIREDO FILHO, D. B.; JUNIOR, J. A. S. Desvendando os Mistérios do Coeficiente de Correlação de Pearson (r). Revista Política HojeISSN: 0104-7094, v.18, n,1, 2010.

FRUMKIN, P.; GALASKIEWICZ, J. Institutional isomorphism and public sector organizations. Journal of public administration research and theory, v.14, n. 3, p.283-307, 2004.

HAMMARFELT, B.; FREDRIK, A. The multi-layered and multilevel use of bibliometric measures in Swedish universities: Isomorphism, translation and strategic choice. In The 20th International Conference on Science and Technology Indicators, Lugano, 2-4 September, 2015.

HAN, S. K. Mimetic isomorphism and its effect on the audit services market. Social Forces, v.73, n. 2, p. 637-664, 1994.

HAVEMAN, H. A. Follow the leader: Mimetic isomorphism and entry into new markets. Administrative science quarterly, p. 593-627, 1993.

ISHIKAWA, M. University rankings, global models, and emerging hegemony: Critical analysis from Japan. Journal of Studies in International Education, v.13, n.2, p. 159-173, 2009.

JARVIS, D. S. Policy transfer, neo-liberalism or coercive institutional isomorphism? Explaining the emergence of a regulatory regime for quality assurance in the Hong Kong higher education sector. Policy and Society, v.33, n. 3, p. 237-252, 2014.
LANGRAFE, T. DE F., BOAVENTURA, J. M. G., DA SILVA, R. S., DA SILVA, D. Grupos Estratégicos: um estudo dos cursos de graduação em Administração na cidade de São Paulo. RIAE. Revista IberoAmericana de Estratégia. v. 8 n.1, p.78-101, 2009.

LARRÁN, M.; HERRERA, J.; ANDRADES, F. J. Measuring the linkage between strategies on sustainability and institutional forces: an empirical study of Spanish universities. Journal of Environmental Planning and Management, v.59, n.6, p. 967-992, 2015.

MACCARI, E. A.; LIMA, M. C.; RICCIO, E. L. Uso do sistema de avaliação da CAPES por programas de pós-graduação em Administração no Brasil. Revista de Ciências da Administração, v.11, n.25, p.68, 2009.

MACCARI, E. A.; DE ALMEIDA, M. I. R.; RICCIO, E. L.; ALEJANDRO, T. B. Proposta de um modelo de gestão de programas de pós-graduação na área de Administração a partir dos sistemas de avaliação do Brasil (CAPES) e dos Estados Unidos (AACSB). Revista de Administração, v.49, n. 2, p. 280-290, 2014.

MARTÍNEZ-FERRERO, J., GARCÍA-SÁNCHEZ, I. $M$. Coercive, normative and mimetic isomorphism as determinants of the voluntary assurance of sustainability reports. International Business Review, v. 26, n.1, p. 102-118, 2017.

MARTINS, C. B., MACCARI, E. A., MARTINS, S. B., SERRA, F. A. The influence of co-authorship networks on the performance of graduate programs in the Brazilian evaluation system. In: Proceedings of PICMET'14 Conference: Portland International Center for Management of Engineering and Technology; Infrastructure and Service Integration. IEEE, p. 1569-1584, 2014.

MEYER, J. W.; ROWAN, B. Institutionalized organizations: Formal structure as myth and ceremony. American Journal of Sociology, v.83, n. 2, p. 340-363, 1977. 
MINDALI, O.; RAVEH A.; SALOMON, I. Urban density and energy consumption: a new look at old statistics. Transport. Res. v. 38, p.143-162, 2004.

MOROSINI, M. C. Qualidade da educação universitária: isomorfismo, diversidade e eqüidade. Interface comun. saúde educ, v.5, n.9, p. 89-102, 2001.

MURTEIRA, B. J. F. Estatística descritiva-análise exploratória de dados. 1993.

NASCIMENTO, L. F. Modelo Capes de avaliação: quais as consequências para o triênio 2010-2012? Administração: Ensino e Pesquisa, v. 11, n.4, p. 579600, 2010.

OLIVER, C. Sustainable competitive advantage: combining institutional and resource $\nabla b a s e d$ views. Strategic management journal, v.18, n.9, p. 697-713, 1997.

PAPADIMITRIOU, A.; WESTERHEIJDEN, D. F. Adoption of ISO囚oriented quality management system in Greek universities. The TQM Journal, v. 22. n. 3, p. 229-241, 2010.

PECI, A. A nova teoria institucional em estudos organizacionais: uma abordagem crítica. Cadernos Ebape. br, v.4, n.1, p.1-12, 2006.

PEDERSEN, E. R. G.; NEERGAARD, P.; PEDERSEN, J. T.; GWOZDZ, W. Conformance and deviance: Company responses to institutional pressures for corporate social responsibility reporting. Business Strategy and the Environment, v. 22, n. 6, p. 357-373. 2013.

PESTANA, M. H.; GAGEIRO, J. N. Análise de dados para ciências sociais: a complementaridade do SPSS, 2003.

PRAHALAD, C. K.; HAMEL, G. The core competence of the corporation. Harvard Business Review, mai./jun., p. 79-91. 1990.

QUIVY, R.; VAN CAMPENHOUDT, L. Manual de investigação em ciências sociais. 1998.
RAVEH A. Co-Plot: a graphic display method for geometrical representations of MCDM. Eur. J Opl. Res. v.125, n.3, p. 670-678, 2000.

SAUDER, M.; ESPELAND, W. N. The discipline of rankings: Tight coupling and organizational change. American sociological review, v. 74, n.1, p. 63-82, 2009.

SCAFUTO, I. C.; BACKES, D.; MACCARI, E. Grupos estratégicos isomórficos: um estudo no ranking da América Economia. Revista de Ciências da Administração, v.19, n. 48, p. 136-149, 2017.

SEGEV, E.; RAVEH, A.; FARJOUN, M. Conceptual maps of the leading MBA programs in the United States: core courses, concentration areas, and the ranking of the school. Strategic Management. v. 20, n. 6, p. 549-565, 1999.

SGUISSARDI, V. A avaliação defensiva no "modelo CAPES de avaliação": É possível conciliar avaliação educativa com processos de regulação e controle do Estado? Perspectiva, v.24, n.1, p.49-88, 2006.

SPAGNOLO, F.; CALHAU, M. G. Observadores internacionais avaliam a avaliação da CAPES. Infocapes-Boletim Informativo da CAPES, v.10, n.1, p.7-34, 2002.

TALBY, D.; FEITELSON, G.; RAVEH A. A co-plot analysis of logs and models of parallel workloads. ACM Trans. on Modeling \& Comput. Simulation (TOMACS). 2007.

TOLBERT, P. S.; ZUCKER, L. G. Institutional sources of change in the formal structure of organizations: The diffusion of civil service reform, 18801935. Administrative science quarterly, p.22-39, 1983.

WEBER, Y.; SHENKAR, O.; RAVEH, A. National and corporate cultural fit in mergers/acquisitions: an exploratory study. Mngt Sci, v. 42, n. 8, p.1215-1227, 1996. 
VOLPATO, G. L.; FREITAS, E. G. D. Challenge in sci-

entific publication. Pesquisa Odontológica Brasileira, v.17, p. 49-56, 2003.

\begin{tabular}{|c|c|c|c|c|c|c|c|c|c|c|c|c|c|c|c|}
\hline FGV/RJ & Organizaç & Métodos & & Finanças & Estratégia & & Gestão Pú & & & & Sociedadt & & & & Economia \\
\hline UFRGS & Organizaç & Métodos & Marketing & Finanças & Estratégia & TI e intelig & & Sustentab & & Inovação & & & & & Economia \\
\hline PUC-RIO & Organizaç & Métodos & Marketins & Finanças & Estratégia & & & & Negócios & & & & & & \\
\hline UFMG & Organizaç & Métodos & Marketing & Finanças & Estratégia & & & & & & Epistemo & & & Logística & \\
\hline UFRJ & Organizaç & Métodos & Marketing & Finanças & Estratégia & Tl e intelis & & & Negócios & Inovação & & Contabilic & & Logística & \\
\hline FGV/SP & Organizaç & Métodos & Marketing & Finanças & Estratégia & TI e inteli & & Sustentab & & & & & Saúde & & \\
\hline USP & Organizaç & Métodos & Marketing & Finanças & Estratégia & TI e inteliq & & Sustentab & egócios & Inovação & & & & Logística & \\
\hline UFLA & Organizaç & Métodos & Marketing & & & & & & & & & & & & Economia \\
\hline UNB & Organizaç & Métodos & & Finanças & & & Gestão Pú & & & & & & & & \\
\hline UFPB/JP & Organizaç & Métodos & Marketing & Finanças & Estratégia & TI e intelis & & & & & & & & & \\
\hline UFRN & Organizaç & Métodos & & Finanças & Estratégia & Tl e intelit & Gestão Pú & & & & & & & & \\
\hline UFSC & Organizaç & Métodos & Marketing & Finanças & & TI e inteli & & & & & Desenv. S & & Gestão Ec & & \\
\hline PUC/SP & Organizaç & Métodos & Marketins & Finanças & Estratégia & & & & & Inovação & & & & & \\
\hline UFBA & Organizaç & Métodos & & & & & Gestão Pú & & & & & & & & \\
\hline UFPR & Organizaç & Métodos & Marketing & & Estratégia & TI e inteli & & & & Inovação & & & & & \\
\hline UFPE & Organizaç & Métodos & Marketing & Finanças & Estratégia & TI e inteli & & & & Inovação & jociedad & & & & \\
\hline FURB & Organizaç & Métodos & & & Estratégia & & & & & Inovação & & & & & \\
\hline UPM & Organizaç & Métodos & & Finanças & Estratégia & TI e inteliq & & & & & & & & & \\
\hline UNISINOS & Organizaç & Métodos & Marketing & & Estratégia & & & & Negócios & & & & & & \\
\hline PUC/PR & & Métodos & Marketing & Finanças & Estratégia & & & Sustentab & & & & & & & \\
\hline UFES & Organizaç & Métodos & & & & & & & & & Sociedadt & & & & \\
\hline UDESC & Organizaç & & & & & & Gestão Pú & & & Inovação & & & & & \\
\hline UNIVALI & Organizaç & Métodos & & Finanças & Estratégia & & & Sustentab & & & & & & & \\
\hline USCS & Organizaç & Métodos & Marketing & & & & & & & Inovação & & Desenvol & & Redes & \\
\hline UFSM & Organizaç & Métodos & & & Estratégia & TI e inteli & & & & & & & & & Economia \\
\hline UECE & Organizaç & Métodos & Marketing & & & & & & & Inovação & Sociedadt & & & & \\
\hline UFV & & Métodos & & & & & Gestão Pú & & & & & & & & \\
\hline \begin{tabular}{|l|} 
UNINOVE \\
\end{tabular} & Organizaç & Métodos & Marketing & & Estratégia & & & & & Inovação & & & & & \\
\hline PUC/RS & & Métodos & Marketing & & Estratégia & TI e inteli & & & & & & & & & \\
\hline UCS & Organizaç & Métodos & & & Estratégia & TI e inteli & & Sustentab & & & & & & Logística & \\
\hline UNIR & Organizaç & Métodos & & & Estratégia & & & Sustentab & & & & & & & \\
\hline FEI & & Métodos & Marketing & & & & & Sustentab & & Inovação & & & & & \\
\hline UNIGRANA & Organizaç & Métodos & & & Estratégia & & & Sustentab & & & & & & & \\
\hline UFMS & & Métodos & & & Estratégia & & & Sustentab & & & & & Agronegó & & \\
\hline UNAMA & Organizaç & Métodos & & & Estratégia & & & Sustentab & & & & Desenvol & & & \\
\hline UEM & Organizaç & & Marketing & & Estratégia & & & & & & Sociedadt & & & & Empreend \\
\hline ESPM & & Métodos & Marketing & & Estratégia & & & & & Inovação & & & & Gestão & \\
\hline
\end{tabular}

Figura 10 Classificação das disciplinas ofertadas pelos PPGAs em eixos temáticos

Fonte: dados da pesquisa (2017). 